\title{
1 Identification of Hotspots of Rainfall Variation 2 Sensitive to Indian Ocean Dipole Mode through 3 Intentional Statistical Simulations
}

4

5 Jong-Suk Kim ${ }^{1}$, Phetlamphanh Xaiyaseng ${ }^{1}$, Lihua Xiong ${ }^{1}$, Sun-Kwon Yoon ${ }^{2, *}$, Taesam Lee,

$6{ }^{1}$ State Key Laboratory of Water Resources and Hydropower Engineering Science, Wuhan

7 University, Wuhan, 430072, P.R. China; jongsuk@whu.edu.cn (J.K.); lar99@yahoo.com

8 (P.X.); xionglh@whu.edu.cn (L.X.)

$9 \quad{ }^{2}$ Department of Safety and Disaster Prevention Research, Seoul Institute of Technology, Seoul

10 03909, Republic of Korea

$11{ }^{3}$ Department of Civil Engineering, ERI, Gyeongsang National University, 501 Jinju-daero,

12 Jinju, Gyeongnam, South Korea, 660-701

$13{ }^{*}$ Correspondence: skyoon@ $@$ sit.re.kr (S.Y.); tae3lee@gnu.ac.kr (T.L.)

14

15 Abstract. This study analyzed the sensitivity of rainfall patterns over the Indochina

16 Peninsula (ICP) to sea surface temperature in the Indian Ocean based on statistical

17 simulations of observational data. Quantitative changes in rainfall patterns over the ICP

18 were examined for both wet and dry seasons to identify hotspots sensitive to ocean

19 warming in the Indo-Pacific sector. Rainfall variability across the ICP was confirmed

20 amplified by combined and/or independent effects of the El Niño-Southern Oscillation

21 and the Indian Ocean Dipole (IOD). During the years of El Niño and a positive phase of

22 the IOD, rainfall is less than usual in Thailand, Cambodia, southern Laos, and Vietnam.

23 Conversely, during the years of La Niña and a negative phase of the IOD, rainfall

24 throughout the ICP is above normal, except in parts of central Laos and northern

25 Vietnam. This study also simulated the change of ICP rainfall in the wet and dry

26 seasons according to intentional IOD changes, and IOD-sensitive hotspots were 
27 verified through quantitative analysis. The results of this study provide clear

28 understanding both of the sensitivity of regional precipitation to the IOD and of the 29 potential future impact of statistical changes regarding the IOD in terms of

30 understanding regional impacts associated with precipitation in a changing climate.

31 Keywords: Rainfall variability, Indian Ocean Dipole, ENSO, IBB simulation

\section{1. Introduction}

34 Spatiotemporal variation in precipitation extremes can result from amplification of changes in atmosphere-ocean interactions and intensification of the hydrological cycle on both regional and global scales attributable to the effects of global climate change

37 (Allan and Soden, 2008; Kim and Jain, 2011; Ge et al., 2017; Kang et al., 2017; Kim et al., 2017; Gao et al., 2019). Changes in the magnitude and frequency of regional rainfall

39 are related closely to the occurrence of floods and droughts. They have important

40 implications not only in terms of their socioeconomic impact, but also in relation to the

41 management of local and/or regional hydropower, irrigation, and environmental water

42 resources (Chi et al., 2016; Gu et al., 2017; Choi et al., 2018). The occurrence of

43 extreme precipitation, which is highly likely to continue into the future, is increasingly

44 regarded as an area of concern by the public because many countries have experienced 45 such extreme events in recent years (Croitoru et al., 2013; IPCC, 2013; Hirsch and

46 Archfield, 2015; Chi et al., 2016; Donat et al., 2016). In particular, there has been rapid

47 increase in both the amount of damage and the number of fatalities associated with the

48 occurrence of extreme rainfall in developing countries because of their vulnerable

49 infrastructure, high density of human activities, and poor practices of land use and

50 development (Mirza, 2003; Yin et al., 2011). 

short-term behavior within the global climate system (Chen and Cane, 2008),

53 characterized by irregular but periodic change in the behavior of winds and sea level

54 temperatures over the tropical eastern Pacific Ocean. Since the 2000s, new forms of El

55 Niño have appeared more frequently in the central Pacific (Ashock and Yamagata,

56 2009; Pradhan et al., 2011). However, little is yet known about the causes of these new

57 types of El Niño, some of which have been reported to have noticeable effect on the supply of warm seasonal freshwater and hydrological extremes in Pacific Rim countries (Kim et al., 2012; Yoon et al., 2013; Son et al., 2014; Wang et al., 2014; Kim et al., 2017). Research over the past two decades has identified a distinct climate

61 anomaly in the Indian Ocean, known as the Indian Ocean Dipole (IOD) (Piechota et al.,

62

63 1998; Saji et al., 1999; Mahala et al., 2015; Lqbal and Hassan, 2018). The IOD is an atmosphere-ocean coupling mode characterized by the opposition of anomalies of sea surface temperature (SST) in the west and east of the tropical Indian Ocean (Piechota et al., 1998; Saji et al., 1999; Webster et al., 1999). A positive (negative) IOD pattern is characterized by water warmer (cooler) than normal in the western tropical Indian Ocean $\left(10^{\circ} \mathrm{S}-10^{\circ} \mathrm{N}, 50^{\circ}-70^{\circ} \mathrm{E}\right)$ and water cooler (warmer) than normal in the southeastern tropical Indian Ocean $\left(10^{\circ} \mathrm{S}\right.$ to the equator, $\left.90^{\circ}-110^{\circ} \mathrm{E}\right)$. These events usually begin around May or June and they terminate rapidly in early winter after reaching a peak between August and October (Saji et al., 1999). Long-term climatic change has high correlation with large-scale atmospheric teleconnections and it has been reported predictable in relation to the behavior of nonlinear climate systems, particularly in terms of ocean-related climatic drivers such as ENSO and the IOD mode (Piechota et al., 1998; Saji et al., 1999). ENSO and IOD patterns are known as leading causes of large atmospheric change and they are related closely to seasonal variations in 
76 precipitation in the Indian Ocean region and around the world (Ashok et al., 2001;

77 Ashok et al., 2003; McFadden et al., 2006; Pradhan et al., 2011).

78 Recent studies have suggested that the observed slowdown in the rise of global

79 mean surface atmospheric temperature is related closely to the considerable transport of

80 heat from the Pacific Ocean into the Indian Ocean via the Indonesian Throughflow

81 (Kosaka and Xie, 2013; Lee et al., 2015; Liu et al., 2016; Zhang et al., 2018).

82 Investigation of Indo-Pacific thermocouples can help both to improve understanding of

83 regional-scale climatic variability that is globally relevant and to diagnose

84 quantitatively such variability in a changing climate (Zhang et al., 2018). However,

85 there has been little previous quantitative research on rainfall variation across the

86 Indochina Peninsula (ICP) in relation to IOD phenomena and ENSO evolution.

87 Therefore, based on historical observations, this study undertook quantitative analysis

88 of the changes in SST in the Indo-Pacific sector and the associated interseasonal

89 variation of precipitation over the ICP. The study had three primary areas of interest: (1)

90 the spatiotemporal changes in magnitude and frequency of precipitation during the dry

91 and wet seasons, (2) the relationship between the changes in weather extremes and

92 large-scale climatic patterns over the ICP, and (3) identification of IOD-sensitive

93 hotspots using the intentionally biased bootstrapping (IBB) technique based on limited

94 historical observations.

95

96 2. Data and Methods

97 2.1. Precipitation Dataset and Climate Change Indices

98 This study used the high-resolution $\left(0.5^{\circ} \times 0.5^{\circ}\right)$ daily Climate Prediction Center

99 Global Unified Precipitation dataset for 1979-2018, which was obtained from the

100 website of NOAA's Earth System Research Laboratory’s Physical Research Division 
101 (https://www.esrl.noaa.gov/psd/). The Global Precipitation Climatology Center

102 monthly precipitation dataset with $1.0^{\circ} \times 1.0^{\circ}$ spatial resolution for the period 1948

103 2018, which is based on quality-controlled data from 67,200 stations worldwide

104 (Schneider et al., 2016), was also used to identify seasonal precipitation variability

105 over the ICP region $\left(5^{\circ}-25^{\circ} \mathrm{N}, 90^{\circ}-115^{\circ}\right.$ E) (Fig. 1). To identify changes in the

106 frequency and intensity of rainfall, six major climate change indices (Karl et al., 1999)

107 based on the daily Climate Prediction Center data from 1979-2018 were analyzed for

108 both the wet season (May-October) and the dry season (November-April). These

109 indices included the seasonal total precipitation (PRCPTOT) on wet days, seasonal

110 total of the 95th percentile of precipitation (R95pTOT) on wet days $(\geq 1.0 \mathrm{~mm})$,

111 seasonal maximum 1-day precipitation (RX1day), simple precipitation intensity index

112 (SDII) with a daily precipitation amount on wet days of $\geq 1.0 \mathrm{~mm}$, maximum number of

113 consecutive dry days (CDD) with a daily precipitation amount of $<1.0 \mathrm{~mm}$, and

114 maximum number of consecutive wet days (CWD) with a daily precipitation amount of

$115 \geq 1.0 \mathrm{~mm}$.

116

117 2.2. Indian Ocean Dipole (IOD) and El Niño-Southern Oscillation (ENSO)

118 The monthly SST anomaly (SSTA) from NOAA's Extended Reconstructed Sea

119 Surface Temperature (ERSST) dataset v5 in the Tropical Indian Ocean (TIO) was

120 used to calculate the IOD mode index. This is defined as the SSTA difference

121 between the western $\left(10^{\circ} \mathrm{S}-10^{\circ} \mathrm{N}, 50^{\circ}-70^{\circ} \mathrm{E}\right)$ and southeastern $\left(10^{\circ} \mathrm{S}\right.$ to the equator,

$12290^{\circ}-110^{\circ}$ E) regions of the TIO (Saji et al., 1999). From 1948-2017, a 3-month running

123 average was applied to the IOD mode index data (August-September-October), which

124 is the peak phase period, with $\pm 1 \sigma$ to determine the years with positive and negative

125 modes of the IOD (Fig. 2). To characterize different types of ENSO event, monthly 

period 1948-2018 were used for El Niño development phases (December-January-

128 February). In this study, the pattern of El Niño was divided into two groups depending

129 on where the peak and persistent anomalies in SST occurred in the tropical Pacific: (1)

130 Eastern Pacific (EP); El Niño occurring in the EP and (2) Central Pacific (CP); El Niño

131 emerging in the CP. This study employed two new indices (Eq. 1) to identify the two

132 types of El Niño event through a simple transformation of the Niño3 and Niño4 indices,

133 as proposed by Ren and Jin (2011):

$$
\begin{gathered}
N_{C T}=N_{3}-\alpha N_{4} \\
N_{W P}=N_{4}-\alpha N_{3},
\end{gathered} \quad \alpha=\left\{\begin{array}{l}
0.4, N_{3} N_{4}>0 \\
0, \text { otherwise } .
\end{array}\right.
$$

Here, $\mathrm{N}_{3}$ and $\mathrm{N}_{4}$ indicate the Niño3 and Niño4 indices, respectively.

\subsection{Trend Detection}

141 A nonparametric Mann-Kendall test is commonly used to detect a monotonic pattern in

142 a time series of climate data based on the null hypothesis that the data are independent

143 and sorted randomly (Mann, 1945; Kendall, 1990). The null hypothesis $H_{0}$ is random in

144 the order of the sample data $\left(X_{i}, i=1,2 \ldots, n\right)$ and it has no trend, whereas the alternative

145 hypothesis $H_{I}$ represents the monotonous tendency of $X$. The $S$ statistic for Kendall's

146 tau is calculated as follows: 


$$
S=\sum_{i=1}^{n-1} \sum_{j=i+1}^{n} \operatorname{sgn}\left(X_{j}-X_{i}\right)
$$

148 and

$$
\operatorname{sgn}\left({ }_{-}\right)=\left\{\begin{array}{rl}
1 & \text { if }_{-}>0 \\
0 & \text { if }_{-}=0 \\
-1 & \text { if }_{-}<0
\end{array} .\right.
$$

$$
\mathrm{E}(\mathrm{S})=0,
$$

$$
V(S)=\frac{n(n-1)(2 n+5)-\sum_{m=1}^{n} t_{m} m(m-1)(2 m+5)}{18}
$$

153 where $t_{m}$ measures the ties of extent $m$. The standardized test statistic $Z$ is estimated as

154 follows:

155

$$
Z=\left\{\begin{array}{cc}
\frac{S-1}{\sqrt{V(S)}} & S>0 \\
0 & S=0 \\
\frac{S+1}{\sqrt{V(S)}} & S<0
\end{array}\right.
$$

156 The existence of autocorrelation in a dataset affects the probability of detecting a trend

157 when it does not exist and vice versa, but this is often ignored. Thus, the modified

158 nonparametric trend test developed by Hamed and Rao (1998) was applied in this

159 study. The corrected $Z$ value is derived as follows:

$$
Z=\left\{\begin{array}{cc}
\frac{S-1}{\sqrt{V^{*}(S)}} & S>0 \\
0 & S=0 \\
\frac{S+1}{\sqrt{V^{*}(S)}} & S<0
\end{array}\right.
$$

161 where

$$
V^{*}(S)=V(S) * \frac{n}{n_{S}^{*}},
$$




$$
\frac{n}{n_{S}^{*}}=1+\frac{2}{n(n-1)(n-2)} * \sum_{i=1}^{n-1}(n-i)(n-i-1)(n-i-2) \rho_{S}(i)
$$

164 where $\rho_{S}(i)$ is an autocorrelation function of the rank with respect to the observations.

165 The sign of $Z$ represents the trend direction and the magnitude of $Z$ is associated with

166 the significance level, where $|Z|>1.64$ for the $10 \%$ significance level and $|Z|>1.96$ for

167 the $5 \%$ significance level.

168

169 2.4. Intentionally Biased Bootstrapping Method

170 Bootstrapping analysis is a statistical method that can generate replicated datasets from source data, and it can evaluate the variability of their quantiles without performing

172 separate analytical calculations (Davision et al., 2003). However, the intentionally 173 biased bootstrapping (IBB) technique applied in this study is a method that allows

174 assessment of the relative effects of a response variable by deliberately increasing or

175 decreasing the mean of the explanatory variable to a certain level while resampling it

176 with the response variable (Lee, 2017). A brief description of the IBB analysis process

177 is given below.

178 Among $n$ observations $x_{i}(i=1,2,3, \ldots, n)$, suppose that the mean of the 179 generated data is deliberately increased or decreased by $\Delta \mu$ for resampling of the 180 observations with bootstrapping. As a result, high (low) values are likely to be 181 resampled and low (high) values could be less likely to be selected. Thus, IBB can be 182 obtained by allocating different weights $S_{i, n}$ depending on the following observation 183 values (Eq. 10):

$$
S_{i, n}=i / n
$$



resampled data can be expressed as in Eq. 11:

$$
\tilde{\mu}=\frac{1}{\psi} \sum_{i=1}^{n} S_{i, n} x_{i}
$$

189 where $x_{i}$ represents the $i$-th incremental value and $\psi=\sum_{i=1}^{n} S_{i, n}$. The average amount of increase or decrease $\Delta \mu$ is shown in Eq. 12:

$$
\Delta \mu=\frac{1}{\psi} \sum_{i=1}^{n} S_{i, n} x_{i}-\frac{1}{n} \sum_{i=1}^{n} x_{i}
$$
sequence $(r)$; thus, $\Delta \tilde{\mu}(r)$ is derived as follows:

$$
\Delta \tilde{\mu}(r)=\tilde{\mu}(r)-\hat{\mu}=\frac{1}{\psi_{r}} \sum_{i=1}^{n} s_{i, n}^{r} x_{i}-\frac{1}{n} \sum_{i=1}^{n} x_{i}
$$

If the average value of increase or decrease is given as $\Delta \mu$, the weight " $r$ " can be calculated accordingly. In this study, the selection of the weight sequence was performed using a Self-Organizing Migrating Algorithm (Zelinka, 2004) with the objective function to minimize $[\Delta \mu-\Delta \tilde{\mu}(r)]^{2}$. In addition, the IBB technique was employed to generate resampled datasets for the IOD and the response to the intensity and frequency of rainfall to identify IOD-sensitive hotspots over the ICP. The statistical significance of the analysis results was assessed using the significance level of the 95th percentiles.

\section{Results}

\section{3.1. Seasonal Precipitation Patterns across the ICP}

206 The ICP is a region in which monsoon rains occur in different seasons in association with seasonal winds and mountain areas. Geographically, the ICP has the Arakan 
208 Mountains in the west, the Bilauktung Mountains and the Dawna Mountains in the

209 center, and the Annamese Mountains in the east. Meteorologically, the ICP is divided

210 into three monsoon periods: the southwest monsoon during June-November,

211 southeast monsoon during September-November, and northeast monsoon during

212 November-February. This study considered the wet season (May-October) and the

213 dry season (November-April) to identify the potential impact on regional rainfall

214 associated with atmosphere-ocean feedback in the Indian and Pacific oceans.

215 Figure 3 shows the seasonal average precipitation during the wet and dry seasons 216 across the ICP region during 1979-2018. The total precipitation during the wet season 217 across the ICP is about $1000-1500 \mathrm{~mm}$. In addition, it has been confirmed that 218 precipitation variability is dependent on specific regions (Fig. 3a). The precipitation 219 variability was found to differ significantly between inland $(<1000 \mathrm{~mm})$ and coastal areas (>2000 mm). Precipitation on the western coast of Cambodia, coast of western

221 Thailand, and Myanmar during June-November is attributable to the influence of the 222 southwest and southeast monsoons. Moreover, clear difference in precipitation is 223 evident between eastern and western parts of the Arakan Mountains in Myanmar. As 224 water vapor from Bangorman decreases over the mountains, the Arakan Mountains show an arid climate to the east and a pattern of strong precipitation to the west.

During the dry season, total precipitation across the ICP is about $150-200 \mathrm{~mm}$, 227 indicating that rainfall variability is not significantly dependent on specific regions 228 (Fig. 3b). In particular, in the dry season, because of the influence of the northeast 229 monsoon during November-February, high rainfall is received in central coastal areas 230 of Vietnam, e.g., near the city of Danang. Similarly, in the case of Myanmar, eastern 231 parts are dry because of the influence of the Arakan Mountains. The climatic 232 characteristics of the ICP are distinctive not only because of the effects of monsoons 
234 specific temporal effects. The precipitation patterns of the ICP are likely to change

235 according to the characteristics of the wet and dry seasons, as well as because of the

236 influence of ocean-related climate factors (e.g., the IOD and ENSO).

\subsection{Spatiotemporal Variation in Precipitation over the ICP}

239 Figures 4 and 5 illustrate the long-term trend of precipitation over the ICP during 19792018 for the wet and dry seasons, respectively. They show the results of the six major

241 climate change indices that represent the magnitude and frequency of precipitation. For each figure, the direction of the trend is displayed in blue (increase) and red (decrease).

243 Figures 4a, 4b, 5a, and 5b show the long-term trends of PRCPTOT and R95pTOT.

244 These seasonal indices can be used to assess total precipitation. It can be seen that the characteristics of their spatial distribution are similar. During the wet season, there is a noticeable decrease in precipitation at the 5-10\% significance level in northern Cambodia, some parts of Laos, and southern Thailand. In addition, it can be seen that there is a marked trend of increase at the 5-10\% significance level in northwestern

249 Myanmar, parts of western Thailand, central Vietnam, and southern parts of China (Fig. $4 \mathrm{a}$ and $4 \mathrm{~b})$.

During the dry season, there is a noticeable increase in precipitation at the 5-10\% 252 significance level along eastern and southern coastal areas of the ICP (i.e., Vietnam and 253 Cambodia) and some southern coastal regions of Thailand (Fig. 5a and 5b). The 254 R95pTOT climate index also shows a trend of increase in precipitation to the west of 255 the Arakan Mountains in Myanmar (Fig. 5b). Therefore, long-term changes in the 256 pattern of precipitation across the ICP during the wet season show a trend of decrease 257 (increase) in central inland areas (some coastal areas). During the dry season, there is a 
258 general trend of increase in precipitation across the ICP. Notably, the trend of increase

259 in precipitation in southeastern coastal areas appears significant.

260 Figures $4 \mathrm{c}, 4 \mathrm{~d}, 5 \mathrm{c}$, and 5d illustrate the long-term trends in RX1day and SDII. The

261 RX1day and SDII climate indices can be used to assess rainfall intensity. It can be seen that the characteristics of the spatial distribution of the two indices are similar. Moreover, the characteristics of their spatial distribution are also similar to PRCPTOT and R95pTOT. It can be seen that during the rainy season the intensity of rainfall in central and northern Myanmar, central and southern Vietnam, and southern China increases, whereas the rainfall intensity decreases in Laos, Cambodia, northeastern increases across the ICP, although it shows a clear pattern of decrease in Laos, as in the wet season.

Figures $4 \mathrm{e}, 4 \mathrm{f}, 5 \mathrm{e}$, and $5 \mathrm{f}$ show the long-term trends in CDD and CWD. The CDD

271 and CWD indices can be used in assessment of droughts and floods, respectively.

272 Therefore, it is unsurprising that the CDD and CWD indices exhibit opposite spatial

273 distribution characteristics. During the rainy season, the CDD value across the ICP

274 largely tends to increase, although it decreases in some coastal areas, e.g., Vietnam. The

275 CWD index shows the reverse tendency.

276 During the dry season, an increase (decrease) of the CDD (CWD) index can be 277 clearly observed at the 5-10\% significance level (Fig. 5e and 5f). The CDD index 278 increases along the southeast coast of the ICP, e.g., in areas of Vietnam, Cambodia, and 279 southern Thailand, whereas the CWD index exhibits the opposite trend. An increase 280 (decrease) in the CDD index suggests that drought is more (less) likely to occur, while a 281 decrease (increase) in the CWD index means that the occurrence of drought is less 282 (more) likely. Therefore, during the rainy season, floods are expected to increase along 
283 the southeastern coast of the ICP (e.g., in Vietnam, Cambodia, and Thailand), while

284 drought is more likely to occur during the dry season.

285

286

\subsection{Precipitation Variability Associated with the IOD and ENSO}

The IOD, Asian monsoon, and other regional climatological patterns can lead to local or global climate change, particularly in Indian Ocean Rim countries, which can cause severe flooding or droughts depending on IOD variability (Lqbal and Hassan, 2018). Composite analysis can clarify the role of the Southeast Asian Summer Monsoon in precipitation variability across the ICP region associated with years of strong IOD and ENSO, after identifying that tropical climate phenomena are the main factors that influence precipitation variability over the ICP during the wet and dry seasons. However, this role differs depending on the combination of the two climate phenomena and on the season.

Figure 6 shows the results of composite rainfall anomalies (shown as a percentage relative to normal) over the ICP during the wet and dry seasons in relation to the IOD and ENSO. The patterns of rainfall anomalies indicate significant difference between positive and negative IOD years. For positive IOD years, the wet season rainfall (Fig. 6a) shows a decrease of $<20 \%$ in southern parts of the ICP, whereas there is a marked increase in rainfall centered over the Arakan Mountains in western Myanmar. It can be seen that the amount of rainfall received during the dry season (Fig. 6c) is similar to that in the wet season, but there is $40-50 \%$ less rainfall than usual in certain mainland regions of Southeast Asia, especially Yangon and Mawlamyine in Myanmar and in eastern Cambodia.

In negative IOD years, intense positive anomalies of rainfall can be seen in central Cambodia and southern parts of Vietnam. A slight strong-pitched anomaly 
308 pattern is evident during the wet season (Fig. 6b) around the coastline of both

309 Bangladesh and Myanmar, whereas weak-pitched positive anomalies (about 10-15\%

310 relative to the long-term average) are found throughout the ICP. However, changes in

311 rainfall pattern are not evident during the dry season (Fig. 6d), and although the

312 amount varies depending on region, rainfall is generally $>30-50 \%$ above the

313 long-term average. As in the wet season, the dry season also shows relatively strong

314 positive rainfall patterns with positive anomalies of $>80-100 \%$ in Cambodia and both

315 central and southern Vietnam.

316 Sometimes droughts and flooding are likely to converge because of remote

317 connections during IOD-ENSO periods, and they can have significant impact on the

318 modulation of the large-scale oceanic and atmospheric environment, especially in the

319 Indian Ocean and in Pacific Rim countries (Meza, 2013; Mahala et al., 2015; Lqbal

320 and Hassan, 2018). Thus, consideration of both combined and independent effects of

321 ENSO and the IOD on seasonal precipitation variability can provide improved

322 predictive expertise, and reveal new insight into tropical climate change and global

323 warming impacts (Ashok et al., 2001).

324 Figure 7 shows composite rainfall anomalies (November-April) during positive 325 and negative IOD years that coincided with ENSO. During positive IOD and El Niño 326 years (Fig. 7a), there is less rainfall than usual across Thailand, Cambodia, southern 327 Laos, and Vietnam. In particular, southern regions of Myanmar (from Yangon to 328 Mawlamyine) that border the Andaman Sea show a distinct decrease in rainfall by 329 more than $50 \%$ in comparison with the long-term mean (1981-2010). However, in 330 contrast, there is $20-40 \%$ more rainfall than usual in northern parts of the ICP, e.g., 331 northern Myanmar, northeastern parts of Laos, and Vietnam. Furthermore, in 332 Guangzhou in China, rainfall is up to $60 \%$ higher in comparison with average years. 
333 These rainfall signals are stronger in WP El Niño years than in CT El Niño years

334 (figures not shown). During negative IOD and La Niña years (Fig. 7b), rainfall above

335 the long-term average is observed throughout the ICP, except for parts of central Laos

336 and northern Vietnam. The pattern of increased rainfall appears strongly throughout Myanmar and regions around Ho Chi Minh City in Vietnam. However, in the region

338 adjacent to India and Bangladesh, as well as the Shenzhen area of China, strong

339 negative anomalies are evident.

\subsection{Identification of IOD-Sensitive Hotspots through IBB Simulations}

342 Section 3.3 discussed the significant impact on rainfall anomalies in the ICP

343 attributable to the combined or independent effects of ENSO and the IOD. In particular,

344 both positive IOD events and El Niño and negative IOD events and La Niña interact in

345 modulating rainfall anomalies over the ICP. The IOD and ENSO are strongly correlated

346 and their variations are mutually forced or triggered ( $\mathrm{Yu}$ and $\mathrm{Lau}, 2005$; Yuan and $\mathrm{Li}$,

347 2008; Lestari and Koh, 2016). For the period 1979-2017, the correlation between the

348 peak phase of the IOD and the two types of El Niño index proposed by Ren and Jin

349 (2011) was analyzed. The results showed the IOD has strong positive correlation with

350 the CT El Niño $\left(\mathrm{N}_{\mathrm{CT}}\right)(\rho=0.4850, \mathrm{p}$-value $=0.0018)$. However, the IOD also has

351 positive correlation with the WP El Niño $\left(\mathrm{N}_{\mathrm{WP}}\right)$, but not at a statistically significant

352 level $(\rho=0.110, \mathrm{p}$-value $=0.5013)$. These results are also reflected in the results of

353 the IBB simulation (Fig. 8). Figure 8 shows the results of 1000 simulations for the

$354 \mathrm{~N}_{\mathrm{CT}}$ and $\mathrm{N}_{\mathrm{WP}}$ indices performed by applying the IBB technique to the IOD index

355 based on historical observations for the period 1979-2017. For applying a +1SD

356 increase of the IOD, the mean difference between the observation of $\mathrm{N}_{\mathrm{CT}}$ and

357 simulated $\mathrm{N}_{\mathrm{CT}}$ shows a statistically significant increase at the $95 \%$ significance level 
358 (diff. $=0.392$, Interquartile range $(I Q R)=0.228)$. However, the difference in the

359 mean value of the $\mathrm{N}_{\mathrm{WP}}$ index, although increased slightly, is not statistically

360 significant (diff. $=0.097, \mathrm{IQR}=0.094)$. For applying a $-1 \mathrm{SD}$ decrease of the IOD, the

361 simulation results show changes similar to the case with a +1SD increase of the IOD

$362\left(\mathrm{~N}_{\mathrm{CT}}\right.$ : diff. $=0.360, \mathrm{IQR}=0.108, \mathrm{~N}_{\mathrm{WP}}$ : diff. $\left.=0.088, \mathrm{IQR}=0.098\right)$. Therefore, for

363 changes in the IOD, the linear increase (or decrease) in the $\mathrm{N}_{\mathrm{CT}}$ index is more

364 pronounced than the change in the $\mathrm{N}_{\mathrm{WP}}$ index.

365 The spatiotemporal connection between SST and winds shows strong coupling

366 through precipitation and ocean dynamics (Saji et al., 1999). This dipole mode,

367 accounts for about $12 \%$ of SST variability in the Indian Ocean, and its duration of

368 activity can greatly affect both the intensity and the frequency of rainfall in the Indian

369 Ocean Rim countries, including the ICP. Based on statistical simulations of historical

370 observations (1979-2018), Figs. 9 and 10 show rainfall variation and the most

371 sensitive hotspot areas in the wet and dry seasons of the ICP attributable to IOD

372 changes.

373 The spatial distribution of differences in PRCPTOT is shown in Fig. 9, given the

374 condition of a \pm 1 SD increase or decrease of the IOD in the wet season. For a +1 SD

375 increase of the IOD, PRCPTOT is $>90 \%$ higher than usual throughout Myanmar, and

376 weak positive anomaly patterns are evident in southwestern China. In contrast, a

377 pattern of decrease of PRCPTOT of 15-20\% less than the long-term average is evident

378 in Cambodia and southern Vietnam, i.e., in areas of the downstream reaches of the

379 Mekong River. However, no statistically significant changes occur in the central ICP

380 region, except in some parts of central Laos and Thailand. This spatial distribution of

381 rainfall anomaly is also found for the RX1day index, although occasional patterns of

382 increase or decrease are evident and the spatial extent is reduced. In addition, 

index, a statistically significant pattern of decrease is found across Vietnam, Cambodia, and Laos. The most significant changes in the CWD index are across Myanmar (increase of 35-50\%), southern Cambodia, and the southeast coast of Vietnam (decrease of 15-20\%). The other ICP regions generally show a pattern of weak increase in terms of CWD. For a -1 SD decrease of the IOD, PRCPTOT, RX1day, and CWD all show distinct patterns of increase in the Laos and Vietnam basins, while the CDD index shows a predominant pattern of decrease, except in certain areas. Analysis indicates that other regions have a reverse pattern compared with the case of the +1SD

393 increase of the IOD. Consequently, it is determined that changes in rainfall during the wet season in the ICP region are sensitive to changes in the IOD.

Given the condition of a $\pm 1 \mathrm{SD}$ increase or decrease of the IOD for the dry season,

396 the spatial distribution of the rainfall indices is shown in Fig. 10. For a decrease of $397-1 \mathrm{SD}$ of the IOD, there is more rainfall (PRCPTOT and RX1day) than usual throughout the ICP, especially in Laos and Vietnam. For a +1SD increase of the IOD,

399 negative anomaly patterns of PRCPTOT are dominant in southern Vietnam, eastern 400 Cambodia, and northeastern Thailand, while weak patterns of positive anomaly are evident in areas of Myanmar and South China. Compared with the changes in the

402 rainfall indices during the wet season, changes in the rainfall indices are intensified 403 and the spatial influence is more extensive. However, for the CDD and CWD indices, 404 either the positive anomaly patterns are weakened or negative anomaly patterns 405 appear for a +1 SD increase of the IOD. Especially for the CWD index, a pattern of 406 decrease by more than 10-20\% compared with the long-term average is found in

407 Thailand, whereas the Myanmar region shows a pattern of increase of 15-25\%. In 
408 this study, we simulated the changes in both wet and dry season rainfall across the

409 ICP according to intentional IOD changes, and IOD-sensitive hotspots were verified

410 through quantitative analysis. The findings of this study could help elucidate the

411 long-term changes in rainfall expected in the ICP region in a changing climate.

412

413 4. Summary and Conclusions

414 This study analyzed changes in the magnitude and frequency of precipitation during the

415 dry and wet seasons over the ICP, taking into account both the dipole mode in the

416 tropical Indian Ocean and SST warming in the Pacific Ocean. The main results are

417 summarized in the following.

418 1. According to analyses of the long-term trend in seasonal rainfall across the ICP

419 during 1979-2018, rainfall showed significant decreases in northern Cambodia,

420 parts of Laos, and southern Thailand during the wet season (May-October).

421 Moreover, significant increases were evident in northwestern Myanmar, some parts of western Thailand, central Vietnam, and southern China. During the dry season (November-April), PRCPTOT rose noticeably in eastern and southern coastal areas of the ICP (i.e., Vietnam and Cambodia) and some southern coastal regions of Thailand.

2. During the wet season, the CDD index increased and decreased in some coastal areas such as Vietnam. However, during the dry season, increases in CDD and decreases in CWD were evident in the ICP. In particular, a pattern of decline in CWD dominated southeastern coastal areas of the ICP, including Vietnam, Cambodia, and southern Thailand.

3. The IOD showed strong positive correlation with the CT El Niño. However, although the IOD exhibited positive correlation with the WP El Niño, the 

the ICP was confirmed amplified by combined and independent effects of ENSO and the IOD. During years of positive IOD and El Niño, there was less rainfall than usual throughout Thailand and Cambodia, southern Laos, and Vietnam. In particular, the southern part of Myanmar, which borders the Andaman Sea, showed a decrease in regional rainfall of $>50 \%$ in comparison with the long-term average. In contrast, northern parts of India and China, including Myanmar, northeastern Laos, and Vietnam, received 20-40 \% more rainfall than usual. Years with a negative IOD mode and La Niña showed rainfall above the long-term average across the ICP, except for certain parts, e.g., Central Laos and northern Vietnam.

4. Through application of the IBB technique, this study simulated the change of rainfall across the ICP for the wet and dry seasons according to intentional IOD changes, and IOD-sensitive hotspots were verified through quantitative analysis. For the wet season, a $+1 \mathrm{SD}$ increase of the IOD resulted in $>90 \%$ more PRCPTOT than usual across Myanmar in the northwestern ICP. Conversely, in Cambodia and southern Vietnam, rainfall patterns were $15-20 \%$ less than the long-term average in the region of the lower Mekong River. In addition, the CDD index decreased throughout Myanmar by $>25 \%$ compared with the long-term average. The most significant change in the CWD index was in Myanmar, i.e., a 35-50 \% increase. However, a pattern of decrease appeared across the southeastern coast of the ICP in southern Cambodia and Vietnam. For a $+1 \mathrm{SD}$ increase of the IOD in the dry season, negative anomaly patterns of PRCPTOT were found dominant in South Vietnam, eastern Cambodia, and northeastern Thailand, and more rainfall than usual occurred throughout the 

IOD.

461 Although the results of this study are based on limited observations, they provide a clear perspective on the sensitivity of local precipitation to atmosphere-ocean

463 interactions, and they reveal the potential future impact of statistical changes to the IOD,

464 improving our understanding of the associated regional impact on precipitation under

465 the effects of climate change.

466 Author contribution: conceptualization, J.K., S.Y., and T.L.; Formal analysis, J.K.;

470 China (2017YFC0405901), the National Natural Science Foundation of China (No.

471 51525902), and the Ministry of Education "111 Project" Fund of China (B18037), all

472 of which are greatly appreciated.

473 Competing interests: The authors declare that they have no conflict of interest.

\section{References}

475 Allan, R.P. and Soden, B.J.: Atmospheric warming and the amplification of

476 precipitation extremes, Science, 321(5895), 1481-1484,

477 https://doi.org/10.1126/science.1160787, 2008. 
478 Ashok, K., Guan, Z., and Yamagata, T.: Impact of the Indian Ocean Dipole on the 479 relationship between the Indian monsoon rainfall and ENSO, Geophys. Res. Lett., 28, 4499-4502, https://doi.org/10.1029/2001GL013294, 2001.

481

482

Ashok, K., Guan, Z., and Yamagata, T.: Influence of the Indian Ocean dipole on the Australian winter rainfall, Geophys. Res. Lett. 30, 1821, https://doi.org/doi:10.1029/2003GL017926, 2003.

Ashok, K. and Yamagata, T.: The El Niño with a difference, Nature, 461, 481-484, https://doi.org/10.1038/461481a, 2009.

Chi, X., Yin, Z., Wang, X., and Sun, Y.: Spatiotemporal variations of precipitation extremes of China during the past 50 years (1960-2009), Theor. Appl.

Climatol., 124, 555-564, https://doi.org/10.1007/s00704-015-1436-8, 2016.

Croitoru, A.E., Chiotoroiu, B.C., Ivanova, Todorova V., AND Torică, V.: Changes in precipitation extremes on the Black Sea Western Coast, Glob. Planet Chang., 102, 10-19, https://doi.org/10.1016/j.gloplacha.2013.01.004, 2013.

Chen, D. and Cane, M.A.: El Niño prediction and predictability, J. Comput. Phys., 227, 3625-3640, https://doi.org/10.1016/j.jcp.2007.05.014, 2008.

Choi, J.H., Yoon, T.H., Kim, J.S., and Moon, Y.I.: Dam rehabilitation assessment using the Delphi-AHP method for adapting to climate change, Journal of Water Resources Planning and Management, 144(2), 06017007, https://doi.org/10.1061/(ASCE)WR.1943-5452.0000877, 2018. 
498 Davison, A. C., Hinkley, D. V., and Young, G.A.: Recent developments in bootstrap

499 methodology, Statistical Science, 18(2), 141-157, https://doi.org/10.1214/ss/1063994969, 2003. 6, 508-514, https://doi.org/10.1038/nclimate2941, 2016.

504 Gao, Q., Kim, J.S., Chen, J., Chen, H., and Lee, J.H.: Atmospheric in China, Water, 11(2), 232, https://doi.org/10.3390/w11020232, 2019. monsoon precipitation over the Indochina Peninsula in association with ENSO, heavy precipitation across China and its potential links to summer temperature, J. Hydrol., 547, 718-731, https://doi.org/10.1016/j.jhydrol.2017.02.041, 2017. 
520 IPCC, Climate change 2013: the physical science basis. Contribution of Working

521 Group I to the Fifth Assessment Report of the Intergovernmental Panel on

522 Climate Change. Cambridge University Press, UK, 2013.

Iqbal, A. and Hassan, S.A.: ENSO and IOD analysis on the occurrence of floods in Pakistan, Nat. Hazards, 91(3), 879-890, https://doi.org/10.1007/s11069-017-3158-y, 2018.

Karl, T. R., Nicholls, N. and Ghazi, A.: Clivar/GCOS/WMO workshop on indices and indicators for climate extremes workshop summary, in Weather and Climate Extremes, Asheville, North Carolina, pp. 3-7, 3-6 June, 1997.

Kang, H.Y., Kim, J.S., Kim, S.Y., and Moon, Y.I.: Changes in High-and Low-Flow Regimes: a Diagnostic Analysis of Tropical Cyclones in the Western North Pacific, Water Resources Management, 31(12), 3939-3951, https://doi.org/10.1007/s11269-017-1717-3, 2017.

Kendall, M.G., and Gibbons, J.D.: Rank correlation methods. Ed. Edward Arnold., London, England, 1990.

Kim, J. S. and Jain, S.: Precipitation trends over the Korean peninsula: typhoon-induced changes and a typology for characterizing climate-related risk, Environmental Research Letters, 6(3), 034033, https://doi.org/10.1088/1748-9326/6/3/034033, 2011.

Kim, J.S., Zhou, W., Wang, X., and Jain, S.: El Nino Modoki and the summer precipitation variability over South Korea: a diagnostic study, Journal of the 
Meteorological Society of Japan. 90(5), 673-684, https://doi.org/10.2151/jmsj.2012-507, 2012.

543 Kim, J.S., Son, C.Y., Moon, Y.I., and Lee, J.H.: Seasonal rainfall variability in Korea within the context of different evolution patterns of the central Pacific El Niño, Journal of Water and Climate Change, 8(3), 412-422, https://doi.org/10.2166/wcc.2016.020, 2017.

547 Kosaka, Y. and Xie, S. P.: Recent global-warming hiatus tied to equatorial Pacific 548 surface cooling, Nature, 501(7467), 403, https://doi.org/10.1038/nature12534, 5492013.

550 Lee, S.K., Park, W., Baringer, M.O., Gordon, A.L., Huber, B., and Liu, Y.: Pacific

551 origin of the abrupt increase in Indian Ocean heat content during the warming

552 hiatus, Nature Geoscience, 8(6), 445, https://doi.org/10.1038/ngeo2438, 2015.

553 Lee, T.: Climate change inspector with intentionally biased bootstrapping (CCIIBB

554 ver. 1.0)-methodology development, Geoscientific Model Development, 10(2),

555 525-536, https://doi.org/10.5194/gmd-10-525-2017, 2017.

556 Lestari, R.K. and Koh, T.Y.: Statistical evidence for asymmetry in ENSO-IOD

557 interactions, Atmos. Ocean, 54, 498-504,

$558 \quad$ https://doi.org/10.1080/07055900.2016.1211084, 2016.

559 Liu, W., Xie, S.P., and Lu, J.: Tracking ocean heat uptake during the surface warming 560 hiatus, Nature Communications, 7, 10926,

$561 \quad$ https://doi.org/10.1038/ncomms10926, 2016. 
562 Mahala, B.K., Nayak, B.K., and Mohanty, P.K.: Impacts of ENSO and IOD on tropical

563 cyclone activity in the Bay of Bengal, Nat. Hazards, 75, 1105-1125, https://doi.org/10.1007/s11069-014-1360-8, 2015.

565

566

567

568

569
Mann, H.B.: Nonparametric Tests Against Trend, Econometrica 13, 245-259, https://doi.org/10.2307/1907187, 1945.

McPhaden, M.J., Zebiak, S.E., and Glantz, M.H.: ENSO as an integrating concept in Earth Science, Science, 314, 1740-1745, https://doi.org/10.1126/science.1132588, 2006.

Meza, F.J.: Recent trends and ENSO influence on droughts in Northern Chile: an application of the standardized precipitation evapotranspiration index, Weather Clim. Extrem., 1, 51-58, https://doi.org/10.1016/j.wace.2013.07.002, 2013.

Mirza, M.M.Q.: Climate change and extreme weather events: can developing countries adapt? Clim. Pol., 3(3), 233-248, https://doi.org/10.3763/cpol.2003.0330, 2003.

Piechota, T.C., Chiew, H.S., Francis, Dracup J.A., and McMachon, T.A.: Seasonal streamflow forecasting in eastern Australia and the El Niño-Southern Oscillation, Water Res. Res. 34, 3035-3044, https://doi.org/10.1029/98WR02406, 1998.

Pradhan, P.K., Preethi, B., Ashok, K., Krishna, R., and Sahai, A.K.: Modoki, Indian Ocean Dipole, and western North Pacific typhoons: Possible implications for extreme events, J. Geophys. Res. 116: D18108, https://doi.org/10.1029/2011JD015666, 2011.

Ren, H.L. and Jin, F.F.: Nino indices for two types of ENSO, Geophys. Res. Lett., 38, L04704, https://doi.org/10.1029/2010GL046031, 2011. 

the tropical Indian Ocean, Nature, 401(23), 360363, https://doi.org/10.1038/43854, 1999.

Schneider, U., Ziese, M., Meyer-Christoffer, A., Finger, P., Rustemeier, E., and Precipitation Climatology Centre suitable to assess and quantify the global water cycle and resources, Proc. IAHS, 374, 29-34, https://doi.org/10.5194/piahs-374-29-2016, 2016.

Son, C.Y., Kim, J.S., Moon, Y.I., and Lee, J.H.: Characteristics of tropical cyclone-induced precipitation over the Korean River basins according to three Journal of Climatology, 34(8), 2651-2660, https://doi.org/10.1002/joc.3865,

6002014.

601 Webster, P.J., Moore, A.M., Loschnigg, J.P., and Leben, R.R.: Coupled ocean602 atmosphere dynamics in the Indian Ocean during 1997-98, Nature, 401, 356603 360, https://doi.org/10.1038/43848, 1999.

604 Yin, J., Yin, Z.E., Zhong, H.D., Xu, S.Y., Hu, X.M., Wang, J., and Wu, J.P.: 
606 metropolitan area during the transitional economy (1979-2009) in China,

607 Environ Monit. Assess., 177(1-4), 609-621,

608 https://doi.org/10.1007/s10661-010-1660-8, 2011.

609 Yoon, S.K., Kim, J.S., Lee, J.H., and Moon, Y.I.: Hydrometeorological variability in

610 the Korean Han River Basin and its sub-watersheds during different El Niño

611 phases, Stochastic Environmental Research and Risk Assessment, 27(6), 1465-

612 1477, https://doi.org/10.1007/s00477-012-0683-9, 2013.

613 Yu, J.Y. and Lau, K.: Contrasting Indian Ocean SST variability with and without

614 ENSO influence: a coupled atmosphere-ocean GCM study, Meteorol. Atmos.

615 Phys., 90, 179-191, https://doi.org/10.1007/s00703-004-0094-7, 2005.

616 Yuan, Y. and Li, C.: Decadal variability of the IOD-ENSO relationship, Chin. Sci.

617 Bull., 53, 1745-1752, https://doi.org/10.1007/s11434-008-0196-6, 2008. 


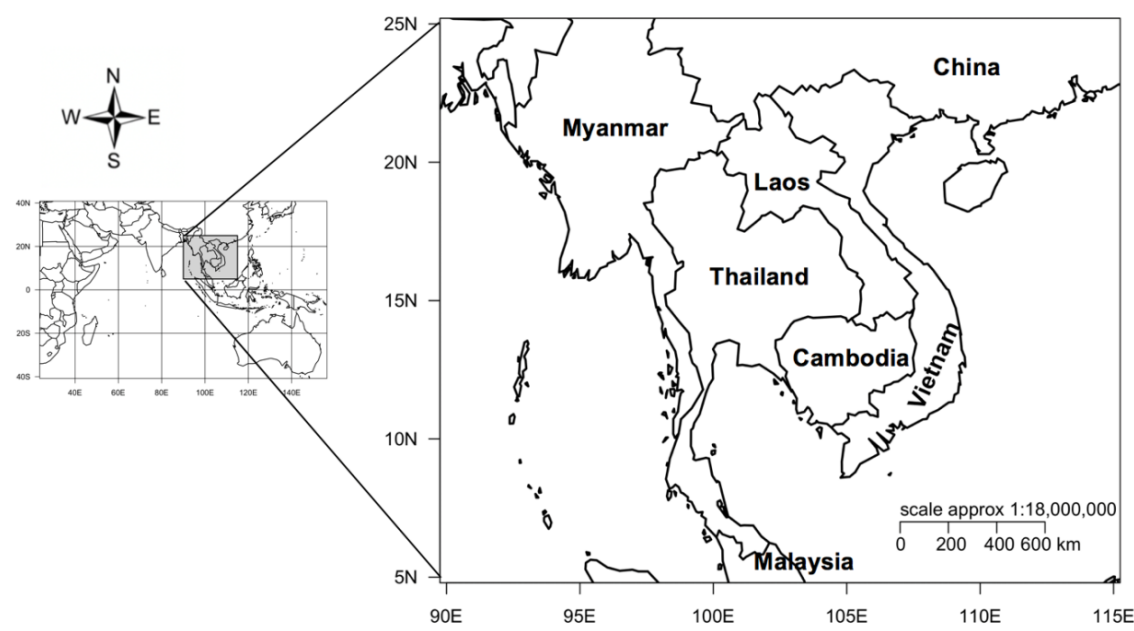

Figure 1. Map of the Indochina Peninsula $\left(5^{\circ}-25^{\circ} \mathrm{N}, 90^{\circ}-115^{\circ} \mathrm{E}\right)$. 

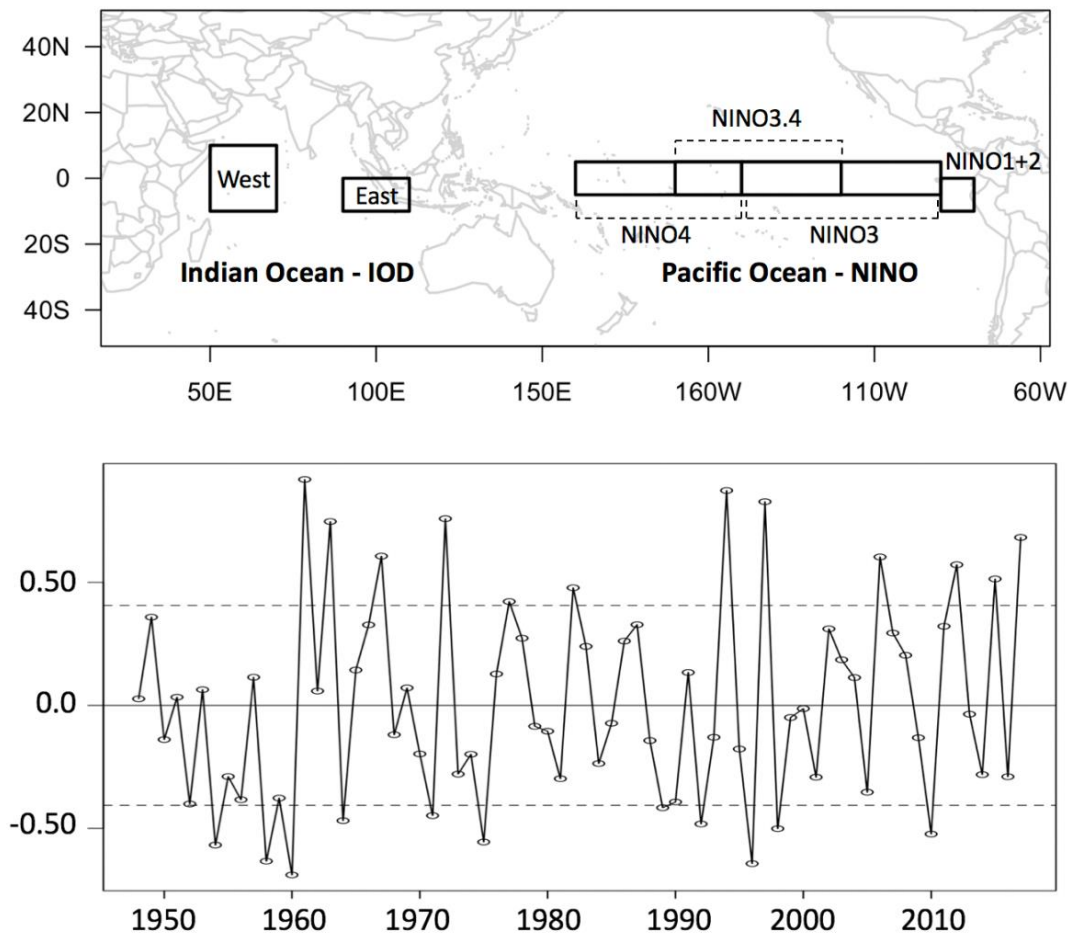

621

622

623

624

625

626

627

628
Figure 2. Dipole mode in the tropical Indian Ocean (TIO) and Niño region in the Pacific Ocean. The Indian Ocean Dipole (IOD) index is defined based on the sea surface temperature anomaly difference between the western $\left(10^{\circ} \mathrm{S}-10^{\circ} \mathrm{N}, 50^{\circ}-70^{\circ} \mathrm{E}\right)$ and southeastern $\left(10^{\circ} \mathrm{S}\right.$ to the equator, $90^{\circ}-110^{\circ} \mathrm{E}$ ) regions of the TIO shown in the upper panel. In the lower panel, the IOD time series during 1948-2017 is shown by the solid line, and the \pm 1 SD of the IOD is marked by dotted lines. 


\section{a. Seasonal Total Precipitation (May-October)}

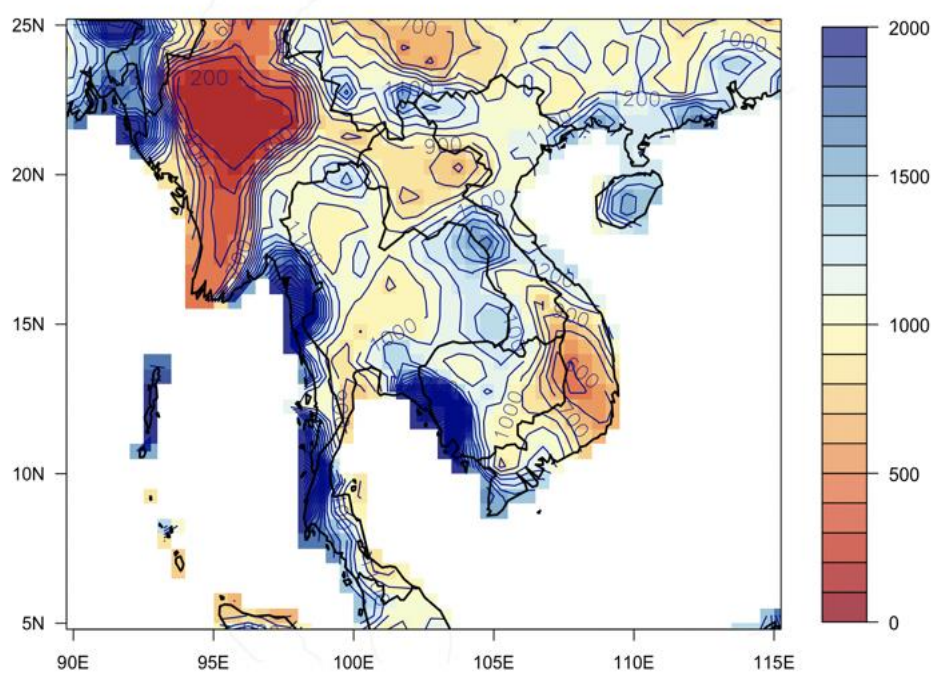

\section{b. Seasonal Total Precipitation (November-April)}

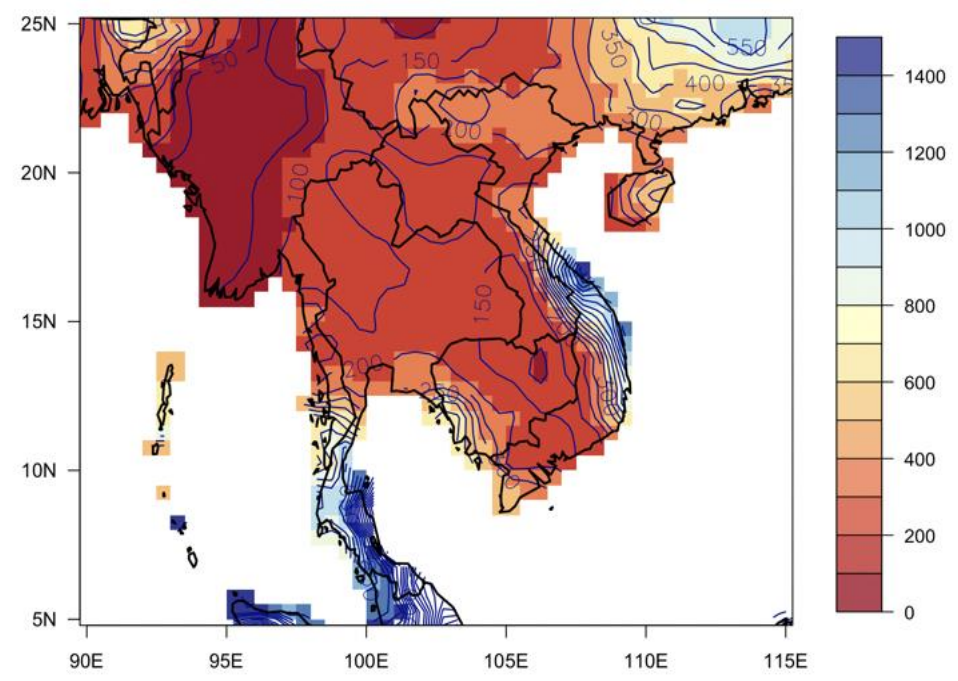



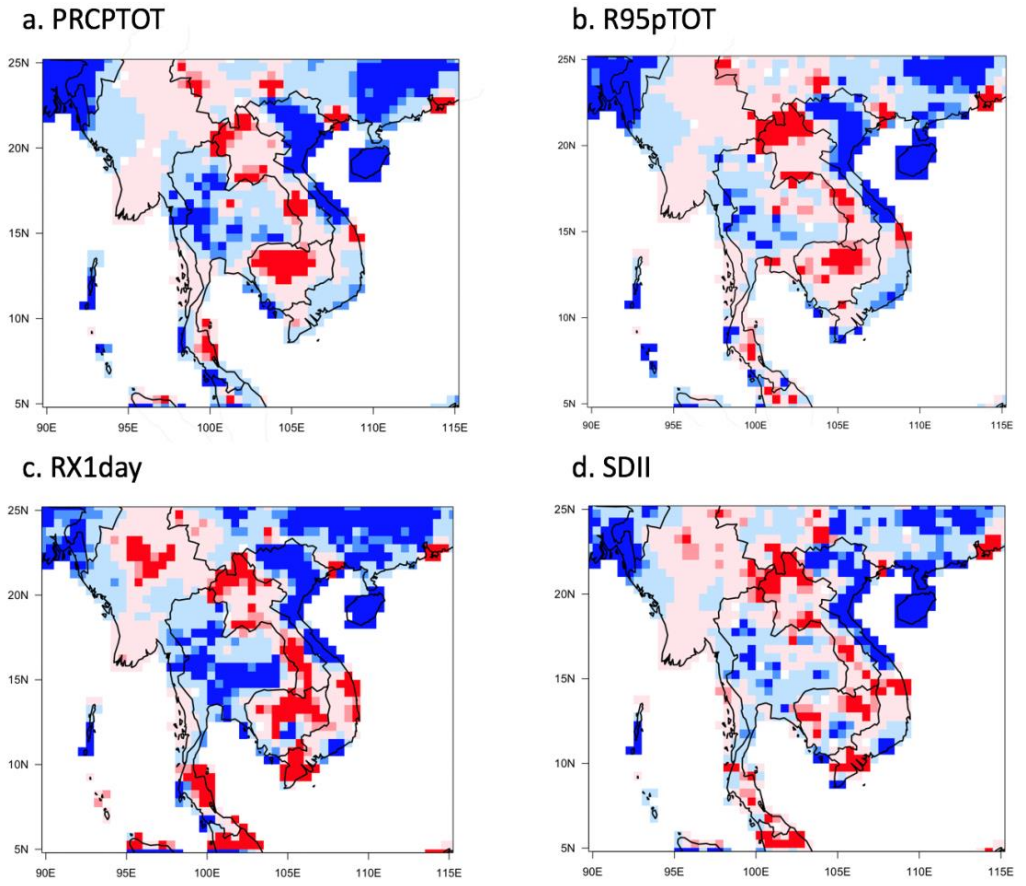

e. $C D D$
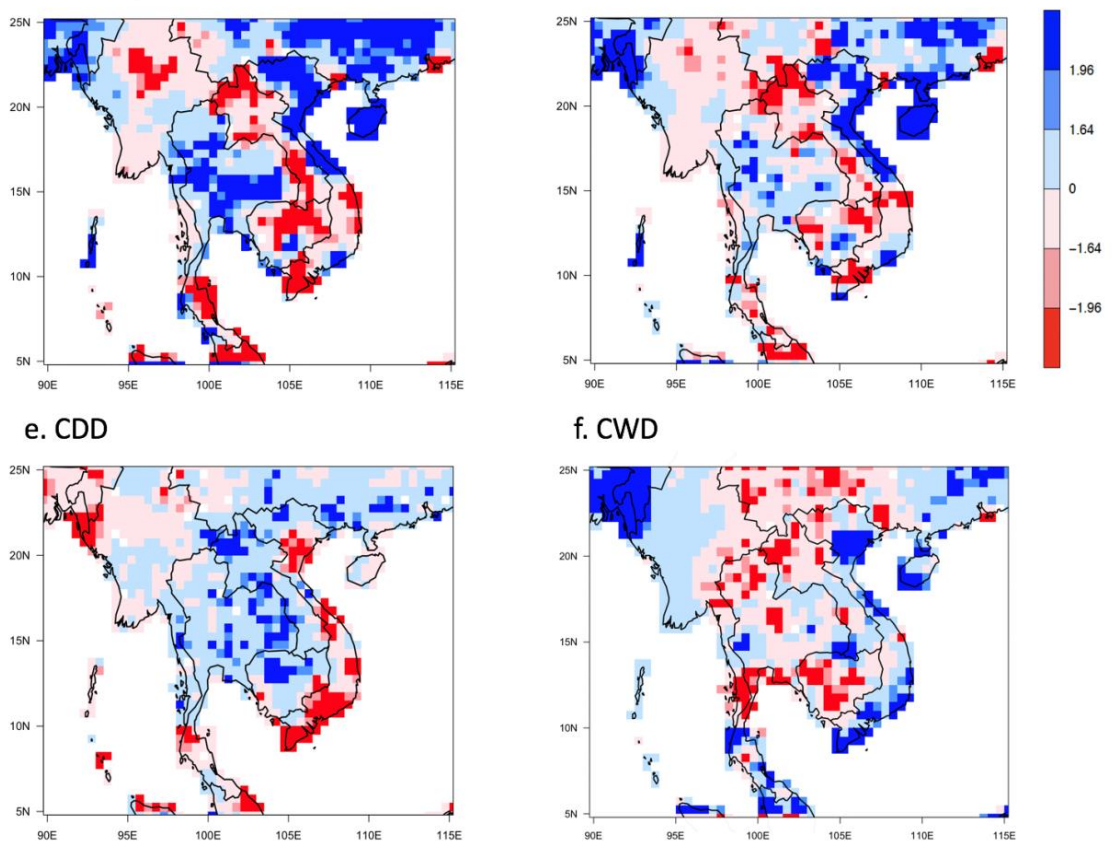

Figure 4. Long-term trend in seasonal precipitation for the wet season (May-October) over the ICP during 1979-2018. (a)-(f) show the analysis results of the six major climate change indices that reflect the magnitude and frequency of precipitation. In each panel, positive and negative trends are displayed in blue and red, respectively. The magnitude of $\mathrm{Z}$ is associated with the significance level, i.e., $|Z|>1.64$ is for the $10 \%$ significance level and $|Z|>1.96$ is for the $5 \%$ significance level. 
https://doi.org/10.5194/hess-2019-217

Preprint. Discussion started: 4 June 2019

(c) Author(s) 2019. CC BY 4.0 License.
Hydrology and

Earth System

Sciences

Discussions a. PRCPTOT

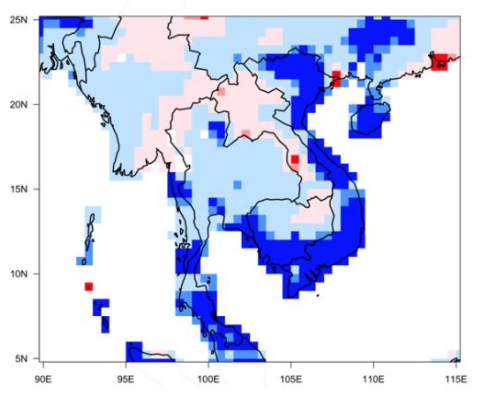

c. RX1day

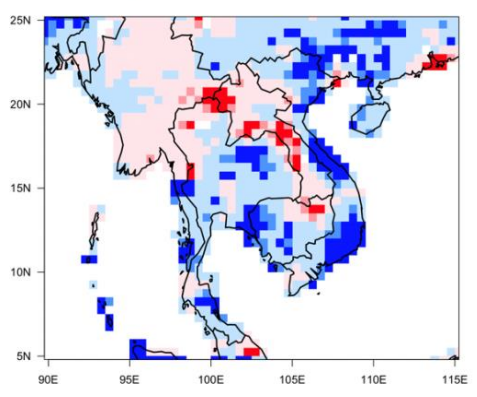

e. CDD

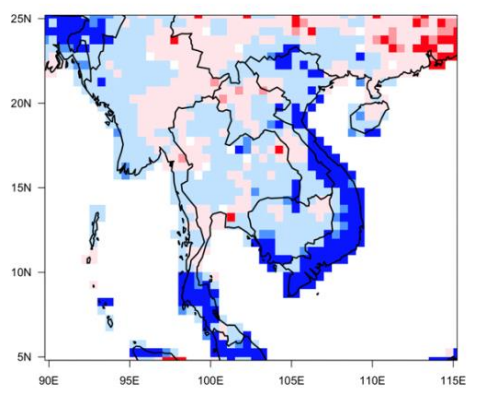

b. R95pTOT

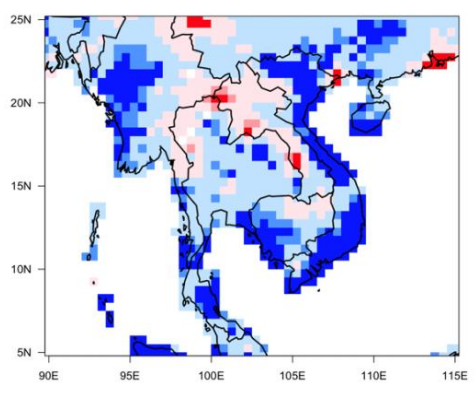

d. SDII

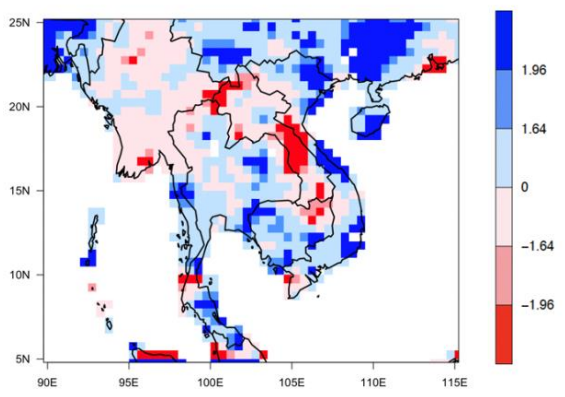

f. CWD

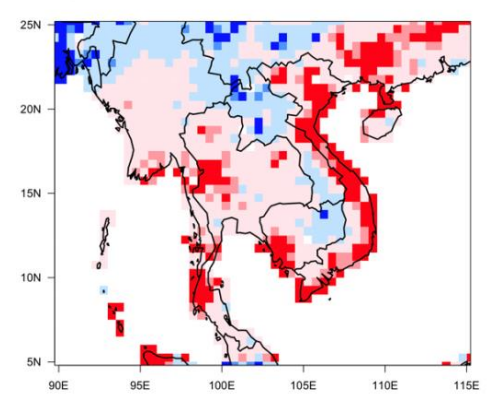

640

641

642

Figure 5. Same as Fig. 4 but for seasonal precipitation during the dry season (NovemberApril). 
a. Rainfall Anomaly (May-Oct) during IOD +

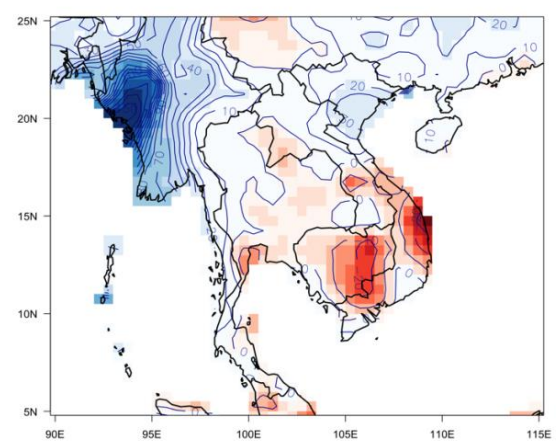

c. Rainfall Anomaly (Nov-Apr) during IOD +

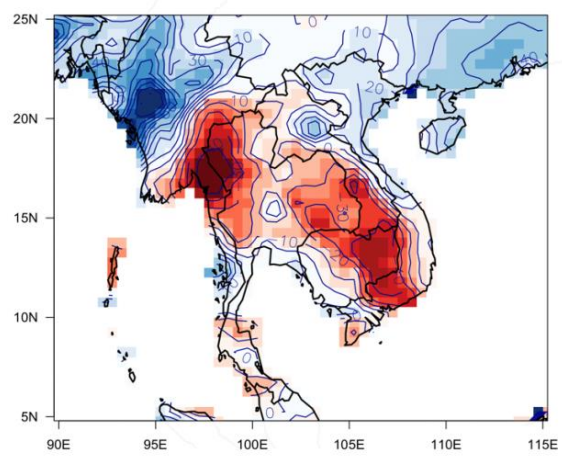

b. Rainfall Anomaly (May-Oct) during IOD -

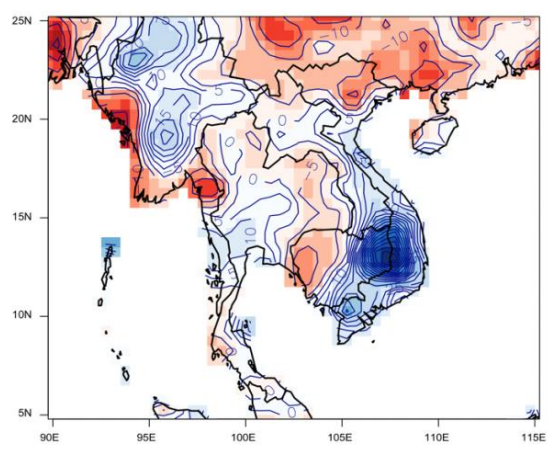

d. Rainfall Anomaly (Nov-Apr) during IOD -

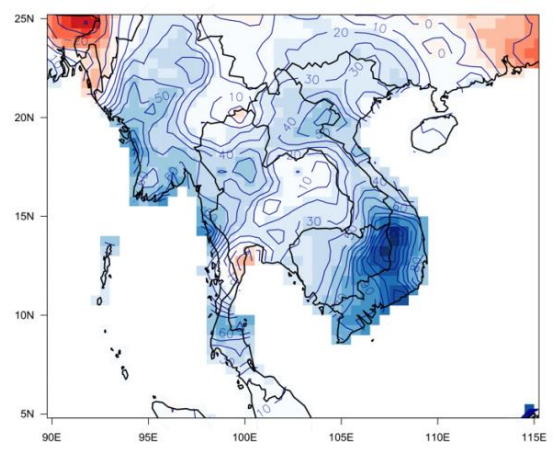

Figure 6. Composite of seasonal rainfall anomaly (\%) during positive and negative IOD 646 years: (a) rainfall anomaly in wet season during positive IOD years, (b) rainfall anomaly in 647 wet season during negative IOD years, (c) rainfall anomaly in dry season during positive IOD 648 years, and (d) rainfall anomaly in dry season during negative IOD years. Positive (negative) 649 values show increasing (decreasing) rainfall departure from the long-term average (1981650 2010). 


\section{a. Rainfall Anomaly during IOD + \& El Nino}

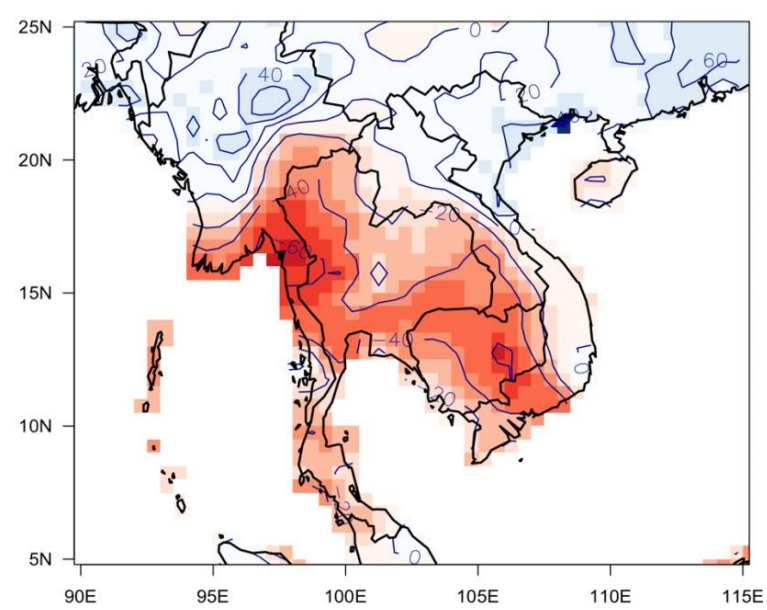

\section{b. Rainfall Anomaly during IOD - \& La Nina}

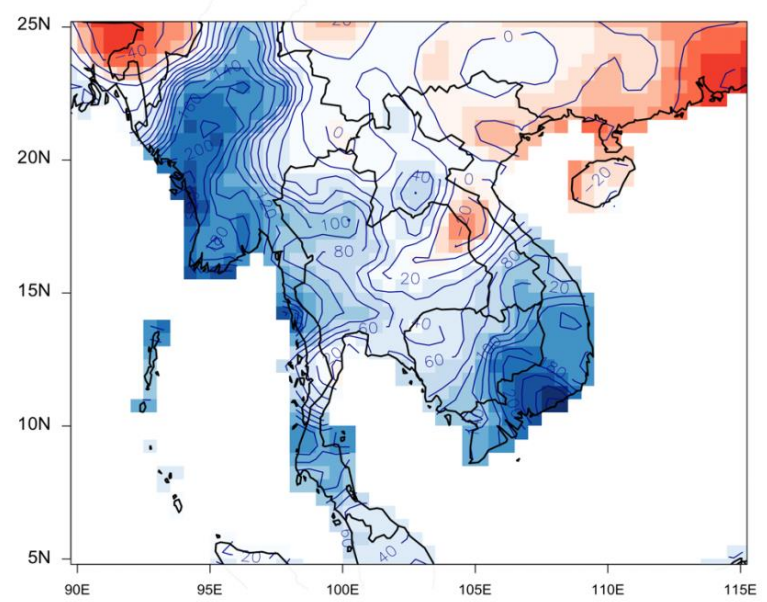

652

653 Figure 7. Composite rainfall anomaly in dry season (November-April) associated with the 654 IOD and ENSO: (a) rainfall anomaly during years with positive IOD and El Niño, and (b) 655 rainfall anomaly during years with negative IOD and La Niña. Positive (negative) values 656 show increasing (decreasing) rainfall departure from the long-term average (1981-2010). 

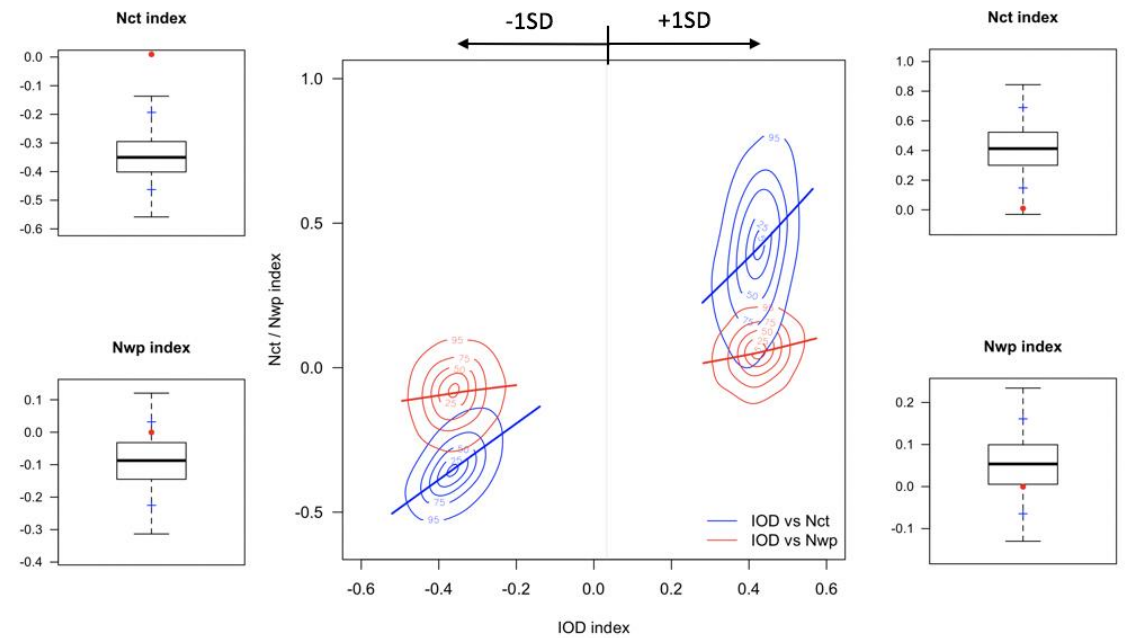

658 Figure 8. Mean differences of the two types of El Niño with \pm 1 SD of the IOD. In the main 659 panel, contours (5th, lower quadrant, median, upper volatile, and 95th level) summarize the 660 IOD index and Nct or Nwp index using the intentionally biased bootstrapping model. Both 661 left and right panels deliberately apply \pm 1 SD of the IOD to show results of 1000 simulations 662 for the Nct and Nwp indices. Red dots in each panel represent the average value of the 663 observations.

664 

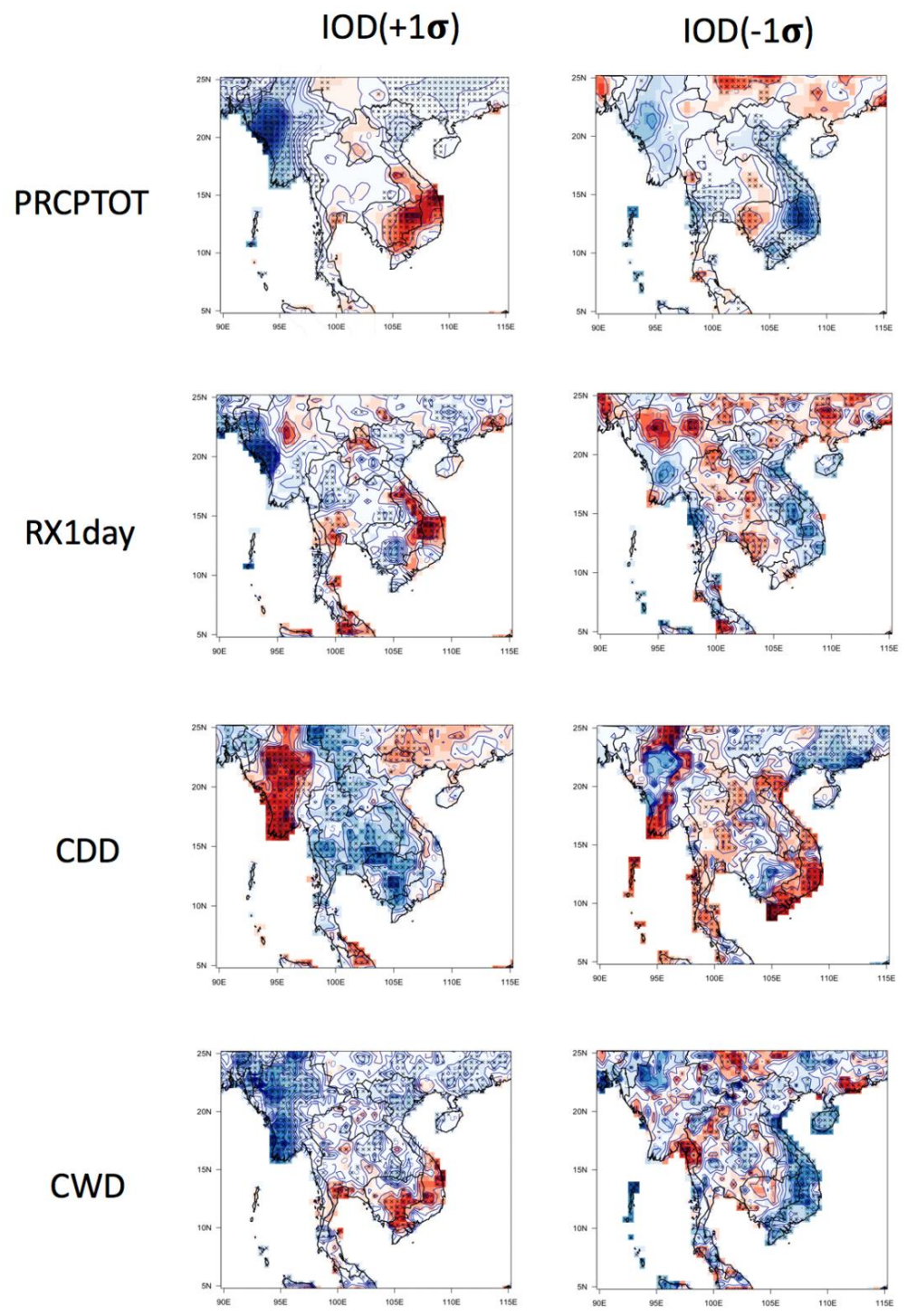

Figure 9. Spatial distributions of the percentage changes in major precipitation indices for the wet season (May-October) over the ICP region for intentional increases (+1SD) or decreases $(-1 \mathrm{SD})$ of the IOD index using the intentionally biased bootstrapping simulation. In each panel, the statistically significant area of change at the $95 \%$ significance level is shown by an 671 "x" symbol. 

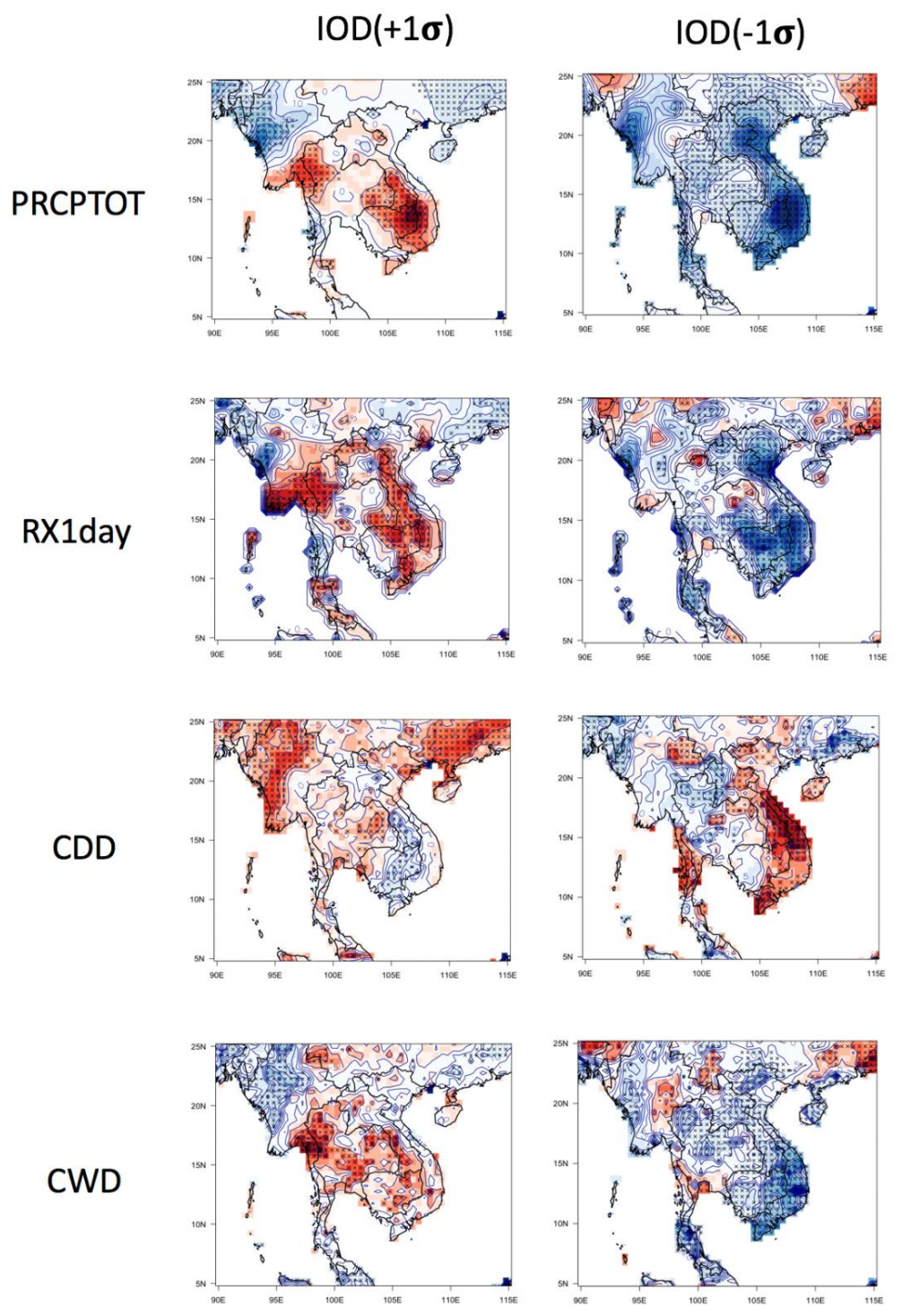

672

673

Figure 10. Same as Fig. 9 but for the dry season (November-April) over the ICP region. 